\title{
Parental Leave and Neuroradiology Fellowships
}

\author{
(D)F.G. Sherbaf, (DD.D.M. Lin, and (DD.M. Yousem
}

\begin{abstract}
BACKGROUND AND PURPOSE: A uniform policy on parental leave in radiology training programs is lacking. Although previous publications have addressed the status of parental leave policy among radiology residency programs, the state of parental leave in radiology fellowships has not been addressed to date. Our aim was to determine the state of parental leave policies in American neuroradiology fellowship programs.
\end{abstract}

MATERIALS AND METHODS: An Internet survey was sent to the directors of neuroradiology fellowship programs listed on the Accreditation Council for Graduate Medical Education Web site $(n=87)$ in January 2020. The questionnaire assessed the policies of the fellowship programs and Program Directors' attitudes toward maternal and paternal leave. Four reminders were sent during the 3 weeks before closing data collection.

RESULTS: The response rate was $76 \%$ (66/87). Ninety-four percent (62/66) of program directors claimed to have a maternal leave policy, of which $51 / 62$ (82\%) were written and 53/62 (85\%) were paid. Additionally, 77\% (51/66) had a policy for paternal leave, of which $80 \%$ (41/51) were written and 76\% (39/51) were paid. The average length of paid leave was $6.7 \pm 3.25$ weeks for new mothers and $2.9 \pm 2$ weeks for new fathers. Unpaid leave was mostly based on the Family and Medical Leave Act. Fellows were responsible for making up call duties during the parental leave in $47 \%$ of the programs. Radiation exposure was restricted in $89 \%$ of the programs during pregnancy. Policies addressed breast feeding and untraditional parenthood in just $41 \%$ of the responding programs. Most program directors supported the development of a unified national policy on maternal (83\%) and paternal (79\%) leave.

CONCLUSIONS: Most neuroradiology fellowship programs have explicit maternal and paternal leave policies that grant paid leave to trainees. Some also offer unpaid leave, mostly through Family and Medical Leave Act guidelines. A uniform policy derived from the Accreditation Council for Graduate Medical Education and/or American Board of Radiology would be useful and overwhelmingly accepted.

ABBREVIATIONS: ABR = American Board of Radiology; ACGME $=$ Accreditation Council for Graduate Medical Education; FMLA $=$ Family and Medical Leave Act; $\mathrm{GME}=$ Graduate Medical Education; $\mathrm{PD}=$ program director

n December 2019, Congress passed the parental leave provision for federal employees as part of a Defense Department spending bill. ${ }^{1}$ This legislation increased the benefits for civilian federal workers so that they could have paid parental leave (military personnel were already receiving 12 weeks' paid leave). Many of the Presidential candidates for 2020 offered programs that would expand paid parental leave to all Americans; the minimum expressed was for 12 weeks, while some, such as Bernie Sanders

Received April 1, 2020; accepted after revision May 10

From the Division of Neuroradiology, the Russell H. Morgan Department of Radiology and Radiological Science, Johns Hopkins Medical Institutions, Baltimore, Maryland.

The authors declare that they had full access to all of the data in this study, and the authors take complete responsibility for the integrity of the data and the accuracy of the data analysis.

D.D.M Lin and D.M. Yousem are co-senior authors.
(6 months) and Andrew Yang (9 months), advocated for longer paid leaves.

To date, most employers support the Family and Medical Leave Act (FMLA), which provides unpaid leave for up to 12 weeks for family and medical reasons. ${ }^{2}$ Of note, the FMLA currently applies to the following:

1. Private sector employers with 50 or more employees.

Please address correspondence to David M. Yousem, MD, MBA, Department of Radiology and Radiological Science, Division of Neuroradiology, Johns Hopkins Medical Institutions, 600 N Wolfe St, Phipps B100, Baltimore, MD 21287; e-mail: dyousem1@jhu.edu

Indicates article with supplemental on-line appendix and table.

http://dx.doi.org/10.3174/ajnr.A6648 
2. Public agencies, including local, state, or federal government agencies, regardless of the number of employees.

3. Public or private elementary or secondary schools, regardless of the number of employees.

To be eligible for the FMLA, the employee must have worked for a covered employer for at least 12 months, during which time there must be at least 1250 hours of service during the 12 months immediately preceding the leave.

The Society for Human Resource Management is one of many groups to advocate for a uniform paid leave policy as part of its "21st Century Workplace Flexibility Policy." 3 However, the need for such a national policy has been debated at least since 1987 with David Berquist's landmark article on the topic. ${ }^{4}$ While government and social welfare groups and the legal profession have been addressing this issue, the Accreditation Council for Graduate Medical Education (ACGME) has taken a more passive role in proposing policies. ${ }^{5}$ The Family and Medical Leave Workgroup in medicine was only recently established (in 2017) to raise awareness of this issue as more and more women enter medical training programs. ${ }^{6}$ The 3 main recommendations proposed by this group include the following:

1. A unified policy of 6 weeks' paid maternity leave for all women across Graduate Medical Education (GME).

2. The option to voluntarily apply the 12-week FMLA standard for all trainees regardless of the duration of employment at their current institution.

3. Institutions should recommend paternity leave and, by extension, leave for the second parent.

Notably some of the training requirements of the ACGME and the American Board of Medical Specialties include time domains that would prohibit a trainee from finishing his or her training on time (for example in a 4-year radiology residency) if a resident had 2 children with two 12-week blocks of FMLA time off. The American Board of Radiology (ABR), as of August 2019, provides this guidance to Program Directors in Radiology: ${ }^{7}$

"Leaves of absence and vacation may be granted to residents at the discretion of the program director in accordance with the institution's rules. Depending on the length of absence granted by the program, the required period of Graduate Medical Education may be extended accordingly. Residency program directors and their institutional GME offices determine the need for extension of residency training. Therefore, it is not up to the ABR to determine graduation dates for individual residents.”

Some have noted that one of the inclusionary provisions of the FMLA may make 1-year fellowship trainees ineligible. As stated above, the FMLA stipulates that the employee must be employed for 12 months and have worked at least 1250 hours during the 12 months before the start of FMLA leave. This would, therefore, not necessarily apply to fellowship trainees in their first year at a new institution.

A uniform policy for dealing with parental leave in fellowship programs has not been clarified by the government (FMLA), the ACGME, the American Board of Medical Specialties, or the ABR. Although previous publications have addressed the status of parental leave policy among radiology residency programs, ${ }^{8}$ the state of parental leave in radiology fellowships has not been addressed to date. In this study, we sought to determine how American neuro-radiology fellowship program directors (PDs) are handling the parental leave issue. We hoped to identify a unifying policy that could be embraced nationally. Among radiology subspecialty fellowship programs, we chose to survey neuroradiology fellowship PDs because of the following: 1) It is in the National Resident Matching Program, so the PD list is readily accessible, 2) it has a well-organized subspecialty society (American Society of Neuroradiology) for obtaining contact information, 3) neuroradiology is one of the largest, historically one of the earliest, and among the best organized ACGME-approved fellowship programs in the field, and 4) as a 1-year required program after residency, it can be said to represent this stage of radiology training, with its inherent parental leave issues.

\section{MATERIALS AND METHODS}

This study qualified as exempt research and was acknowledged by our institutional review board. This study was in accordance with the ethical standards of the institutional and/or national research committee and with the 1964 Helsinki declaration and its later amendments or comparable ethical standards. A 32-question electronic survey was e-mailed to the PDs of neuroradiology fellowship programs in the United States (On-line Table). Individual e-mail addresses were retrieved from the most recent ACGME list of neuroradiology fellowship programs in January 2020. ${ }^{9}$ The survey was composed and distributed in January 2020 using the Qualtrics Research Suite (Qualtrics) administered in our institution, followed by 4 reminders, each $<7$ days apart. Data collection was stopped on February 12, 2020, three weeks after the survey was first distributed.

PDs were requested to provide information about whether a policy for parental leave, formally written versus unwritten, existed in their programs; whether the leave was paid; the average length of allowed paid and unpaid leaves including the need for taking sick and vacation leave first or adherence to FMLA for unpaid leave; arrangements for making up rotations and call duties; adjustments for radiation exposures in the angiography and fluoroscopy rotations during pregnancy; and whether the policy addressed breastfeeding and untraditional male-female parenthood and adoption. The attitude of PDs toward pregnancy during years of training and toward adopting a standardized ACGME/ABR guideline for parental leave policy was also assessed. Inquiry about the program size (defined by the number of graduated fellows per year) and the frequency of making arrangement for parental leave for fellows was also included in the survey. The length of allowed leave was designed as an adjustable bar within the on-line survey. One final open response option allowed PDs to provide free text comments (On-line Appendix). The remaining questions were multiple choice. Skip Logic was used to display only relevant questions, so not all respondents had access to all of the questions. Participation in this survey was voluntary, and all questions were optional. Non-normality of the distribution of the program size was determined by the Shapiro-Wilk test. The relationship between program size 


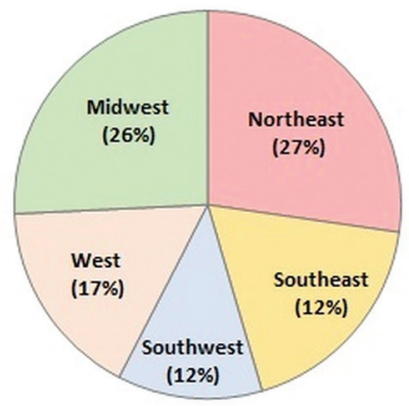

A Geographic Distribution of Responsive Programs ( $n=66)$

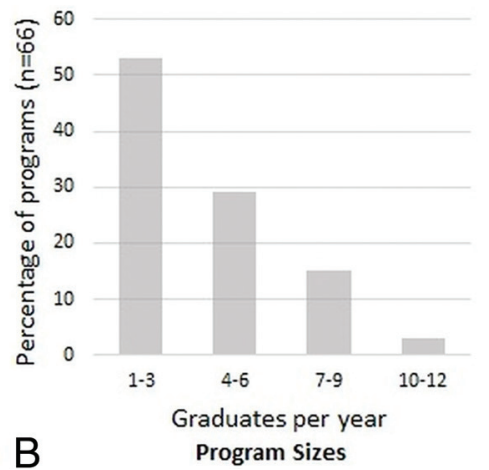

FIG 1. Characteristics of responding neuroradiology fellowship programs. $A$, Pie chart showing the distribution of responses by US regions according to the classification by the American Society of Neuroradiology (percentage of a total of 66 programs). B, Bar graph shows the proportion (percentage of total, $n=66$ ) of programs stratified by program size (number of graduates per year).

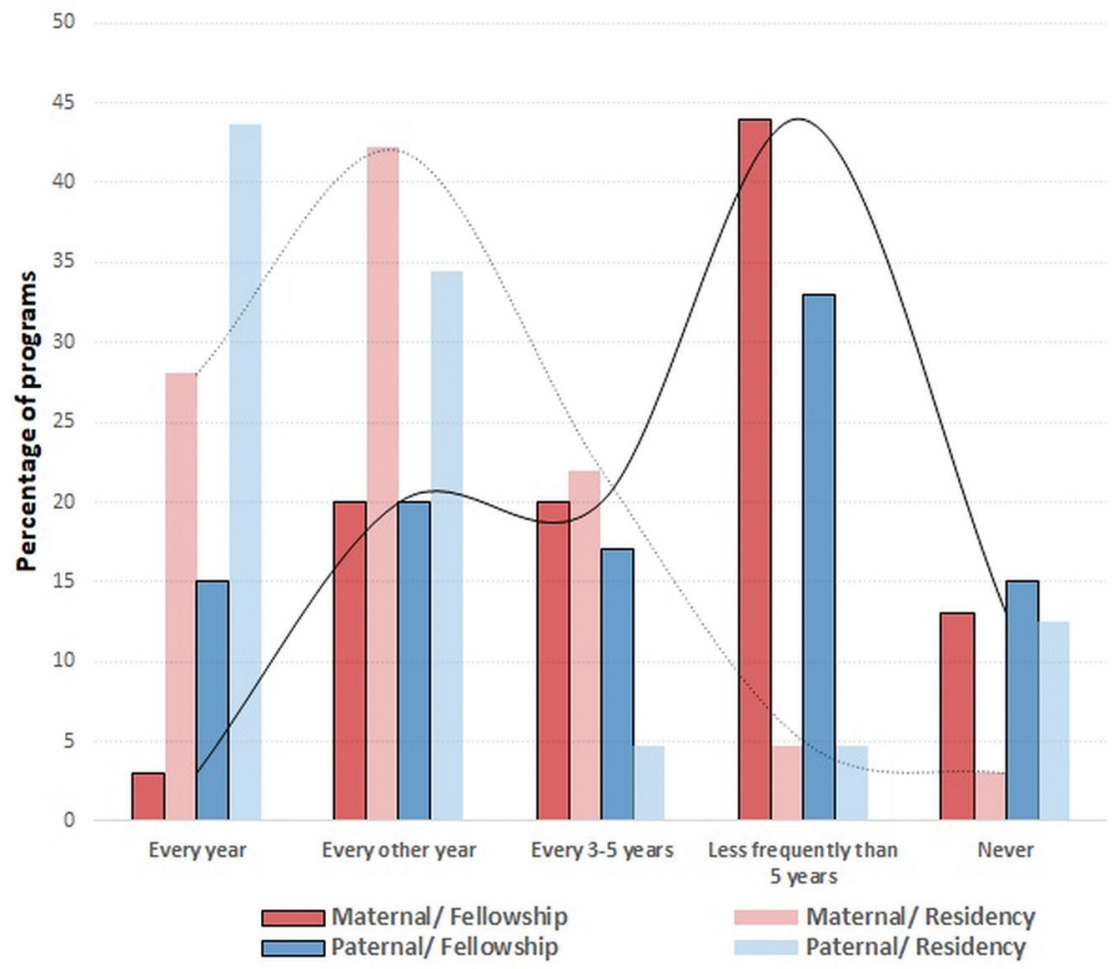

FIG 2. Frequency of arrangements for parental leave in responding neuroradiology fellowshipversus-diagnostic radiology residency programs. Histogram shows the frequency of arrangements for maternal (red) and paternal (blue) leave for fellowship (bold color) versus residency (pale color) programs. The continuous line is the trend line for fellowship programs, while the dotted line represents the trend in residency programs. Radiology residency program data were adopted with permission from Sherbaf et al. ${ }^{8}$

and region was investigated using the Kruskal-Wallis test. The association between program characteristics (including program size and region) and the responses was tested using the Kendall rank correlation. Proportions of programs with a parental leave policy in place were compared between residency programs (data adopted from Sherbaf et $\mathrm{al}^{8}$ ) and fellowship programs using the Fisher exact or $\chi^{2}$ test. All statistical analyses were conducted by using STATA, Version 15 (StataCorp) with $P<.05$ considered significant.

\section{RESULTS}

\section{Characteristics of Respondents}

Eighty-seven neuroradiology fellowship PDs were invited with a response rate of $76 \%(n=66)$. All respondents completed the entire survey. Most of the responses were from PDs in the Northeast and Midwest (53\%; $n=35$ / 66) (Fig 1A). The distribution of collected responses was in concordance with the distribution of neuroradiology fellowship programs throughout the United States (Northeast, 31\%; Midwest, 26\%; Southeast, 17\%; West, $16 \%$; and Southwest, $10 \%) .{ }^{10}$ The program sizes ranged from 1 to 11 (mean, $4 \pm 2.5$ ) graduate fellows per year among 66 responding programs, and slightly more than half of the programs had 3 or fewer fellows (Fig $1 B$ ). There was no significant difference in the average program size among the 5 geographic regions $(P=.77$, KruskalWallis test). Most of the PDs reported that fellows request maternal (44\%, $n=29)$ or paternal $(33 \%, n=22)$ leave at a frequency of less than every 5 years. Of note, paternal leave was provided every year in $15 \%$ of programs versus in only 3\% for maternal leave (Fig 2). In addition, larger programs were more likely to have a fellow on paternal leave $(\tau-\mathrm{B}=0.31, P=.001$, Kendall rank correlation), whereas the frequency of arrangements for maternal leave was not significantly correlated with the program size $(\tau-\mathrm{B}=0.15, P=.11)$.

\section{Maternal Leave}

A policy for maternal leave was known by the neuroradiology PDs in $94 \%$ ( $n=62 / 66)$ of responding programs and was confirmed to be explicitly described in a written document in $82 \%$ of those with a policy $(n=51 / 62)$

(Fig 3). That policy (whether written or not) provided paid leave in 53/62 (85\%). Among those 53 programs with an offer of paid leave, new mothers were asked to first exhaust sick and vacation leave in 13 (25\%) programs. Of those programs not requiring use of sick and vacation leave as part of maternal leave $(n=39 / 53$; $74 \%)$, the average duration of paid leave was $6.7 \pm 3.25$ weeks (range, 2-16 weeks; median, 6 weeks) (Fig 4). Of the 53 programs 

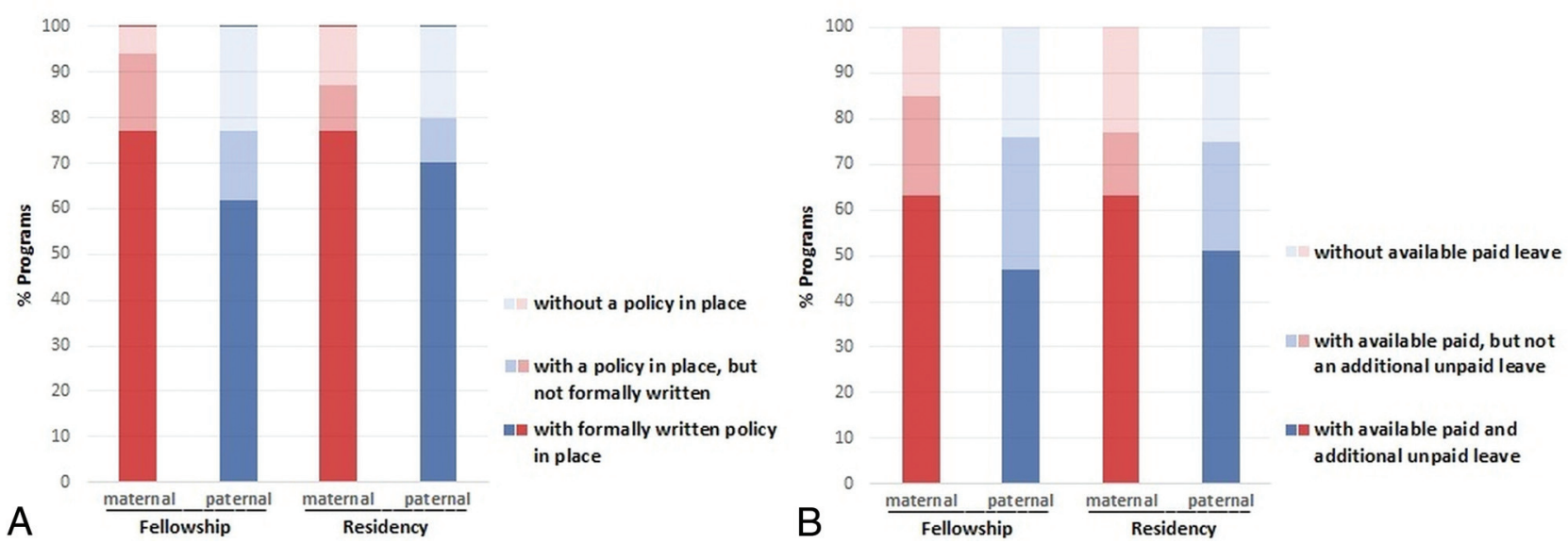

FIG 3. The current status of parental leave policy among responding neuroradiology fellowship-versus-diagnostic radiology residency programs. Bar charts representing the status of a written/unwritten policy for parental leave $(A)$ and the offer of paid and additional unpaid paternal leave among neuroradiology fellowship programs $(B)(n=66 / 87$; response rate, $76 \%)$ versus diagnostic radiology residency programs $(n=74 / 200$; response rate, $37 \%$ ) (adopted with permission from Sherbaf et $\mathrm{al}^{8}$ ) (red, maternal leave; blue, paternal leave). Most programs have a policy in place: fellowship, $94 \%$ with maternal and $77 \%$ with paternal policy; residency, $88 \%$ with maternal and $80 \%$ with paternal policy. Graph $B$ shows PD responses as to whether the leave time is paid. Eighty-five percent of maternal and $76 \%$ of paternal leave is paid among fellowship programs, while $77 \%$ and $75 \%$ of maternal and paternal leave, respectively, is paid among residency programs. Please note that the percentage of programs without a policy in place (graph A) and without an offer of paid leave (graph B) includes nonresponding programs as well. Radiology residency program data were adopted with permission from Sherbaf et al. ${ }^{8}$

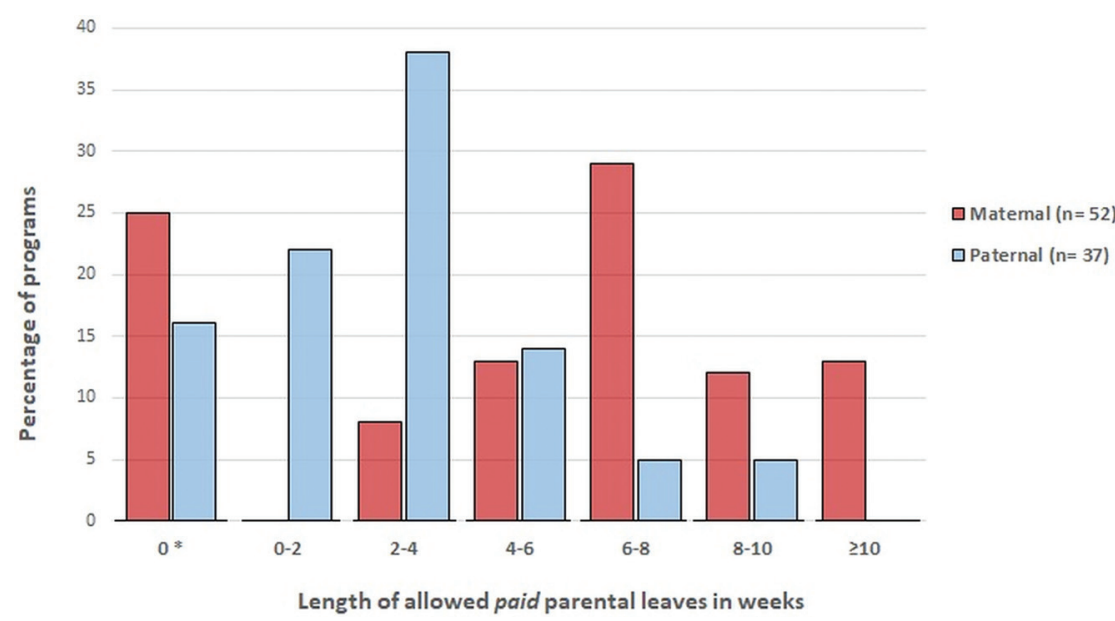

FIG 4. Allowed length of paid parental leave among responding neuroradiology fellowship programs with available paid leave policy. Histogram shows the range of paid maternal (red) and paternal (blue) leave length. The length of paid maternal leave (in addition to sick and vacation leave) is most frequently in the range of $6-8$ weeks, with a mean of 6.7 weeks and median of 6 weeks. The length of paternal leave (in addition to sick and vacation leave) is shorter, at a mean of 2.9 weeks and median of 2 weeks. The asterisk indicates programs that claimed to have a paid parental leave but require fellows to use sick and vacation leave.

that offered paid leave, 39 (74\%) also offered additional unpaid leave. This was mostly based on the FMLA provisions $(71 \%$; $n=22 / 31$ ). The length of leave among programs with a formal policy only allowing unpaid leave $(n=6)$ was also based on the FMLA in 4 programs and was 6 and 12 weeks in the other 2 . The presence of a maternal leave policy, whether written or not, was not significantly correlated with the size of the program $(\tau-\mathrm{B}=$ $0.20, P=.05$, Kendall rank correlation). Likewise, an offer of a paid leave was not correlated with the size of the program $(\tau-\mathrm{B}=$
$0.15, P=.17)$. The frequency of a leave policy in place among fellowship $(n=62 /$ 66) and residency $(n=65 / 74)$ programs $^{8}$ was similar $(P=.21$, Fisher exact test). Women on maternal leave were required to make up on-call responsibility and missed rotations in $47 \%(n=31)$ and $52 \%$ $(n=34)$, respectively.

\section{Paternal Leave}

A policy for paternal leave was known by the neuroradiology PDs in $77 \%(n=51)$ of responding programs and was explicitly described in a written document in $80 \%$ of those with a policy $(n=41 / 51)$ (Fig 3). That policy (whether written or not) provided a mean of $2.9 \pm 2$ weeks (range, 1-8 weeks; median, 2 weeks) of paid leave, in addition to sick and vacation time, to the father among 31 responding programs with a policy $(61 \%$, $n=31 / 51) ; \quad$ an additional 6 programs required fellows to use sick and vacation leave first before allotting any paid paternal leave (Fig 4). Of the 39 programs that offered paid leave, additional unpaid leave was offered in $61 \%(n=24)$, which was mostly based on the FMLA ( $74 \%, n=14 / 19$ of responding programs). A variable range of $1,2,4$, and 6 weeks was offered to new fathers by 4 programs with only unpaid paternal leave available, while 1 program based unpaid leave on the FMLA. The presence of a paternal policy, whether written or not, was not associated with the size of fellowship programs $(\tau$-B $=0.11$, $P=.31$, Kendall rank correlation). By contrast, a paid paternal 
leave was more likely to be available among larger-sized programs above the median ( 3 fellows) $(\tau-\mathrm{B}=0.27, P=.03)$. The frequency of a leave policy in place among fellowship $(n=51 / 66)$ and residency $(n=65 / 74)$ programs was similar $\left(P=.8, \chi^{2}\right.$ test $)$. Fellows on paternal leave were required to make up on-call responsibility and missed rotations in $47 \%(n=31 / 66)$ and $44 \%$ $(n=29 / 66)$, respectively.

\section{Additional Regulations}

Only 27/66 (41\%) programs had formalized their policy on provisions for breast feeding. Forty-one percent $(n=27 / 66)$ had a policy that addressed nontraditional family units; $88 \%$ (24/27) of these provided the same benefits as provided to traditional malefemale family units, whereas PDs of the other 3 programs did not know the details of the benefits. Almost all programs with a policy for addressing the situation of nontraditional parenthood, also had a written parental leave policy in place. All PDs stated that they do not advise against pregnancy during the years of fellowship training. Angiography/fluoroscopy rotations were adjusted for pregnant trainees in $88 \%$ of the programs $(n=59$ / 66 ), of which about $52 \%$ required fellows to make up missed rotations $(n=31 / 59)$.

\section{ACGME Role}

An overwhelming number of neuroradiology fellowship training directors supported the development of a unified policy on maternal $(83 \%, n=55 / 66)$ and paternal $(79 \%, n=52 / 66)$ leave by the ACGME/ABR. Of these, most ( $87 \%$ [ $n=48 / 55]$ for maternal and $90 \%[n=47 / 52]$ for paternal leave) stated they would adhere to that policy if proposed.

\section{DISCUSSION}

This study represents the first study of leave policies in a fellowship program within the radiology subspecialties. It is an underexplored topic most probably related to a much smaller number of physicians-in-training spanning a shorter period of time (1 to 2 years) compared with the number of residents in the traditional 4 -year training program in diagnostic radiology. There are, however, important issues unique to the physicians in fellowship programs as they complete the final stage of training before their professional employment. The results of this survey show that while many neuroradiology fellowship programs have parental leave policies, the parameters of such are nonuniform. The weeks of paid-versus-unpaid leave and the expectations of making up missed call rotations or mandatory weeks on a service are divergent. The application of the FMLA to fellows, allowing them 12 weeks of potentially unpaid leave, is also heterogeneous across maternal and paternal leave. Only 1 program cited the difference between fellows who were previously employed as residents (FMLA-eligible by federal guidelines) versus newly employed fellows from other programs (FMLA-ineligible). Program directors also seem less well-versed about policies associated with breastfeeding or nontraditional family units, including the designations of who could be considered the primary caregiver. The recommendations of a governing body (ie, ACGME or ABR) on the issue of parental leave was strongly welcomed and would be widely accepted according to our survey results.
In comparison with a previous survey of radiology residency program directors, ${ }^{8}$ the frequency of a leave policy in place among fellowship and residency programs is overall similar: Eighty-eight percent had a maternal leave policy, and $80 \%$, a paternal leave policy in the residency programs, compared with our report of $94 \%$ and $77 \%$, respectively, in neuroradiology fellowship (Fig 3). As expected, parental leave was reported to occur more frequently during residency than fellowship, considering the longer duration of the residency program. The total number of neuroradiology fellows compared with diagnostic radiology residents, as well as sex distribution, ${ }^{11}$ most likely accounted for a right-shifted histogram distribution (ie, lower median) of leave frequency in fellowships and the very infrequent arrangements for maternal leave relative to paternal leave on a yearly basis (Fig 2). Similar to the results of residency programs, PDs of larger programs reported having a fellow more frequently on paternal leave, probably at least in part reflecting the higher frequency of such demands in larger programs as well as their ability to better accommodate. Both residency PDs and fellowship PDs identified gaps in policies for breastfeeding and nontraditional parenthood (for a detailed comparison between residency and fellowship survey results, please refer to On-line Table).

The literature on parental leave for fellowships outside radiology is scant. A survey in 2016 also highlighted the nonuniform status of the parental leave among orthopedic surgery residency and fellowship programs. ${ }^{12}$ Of 45 responding PDs in that survey, $98 \%$ and $91 \%$ claimed to have a maternal and paternal leave policy, respectively, providing about 4-6 weeks of leave. However, the leave was paid in only about half of the programs. ${ }^{12}$ Other surveys have mostly assessed the status of paternal leave from the fellows' points of view. For example, a survey of the members of the American Academy of Pediatrics Section on Medical Students, Residents, and Fellowship Trainees in 2013, with 182 responses from fellows, revealed that $30 \%$ of the respondents were not aware of the parental leave policy in their programs. ${ }^{13}$ It also showed that a large number of trainees $(80.5 \%$ of 411 responders) took advantage of parental leave for an average of 11.7 weeks. Longer maternity leave, which was mostly due to breastfeeding, had resulted in the extension of the duration of training. ${ }^{13}$ A negative stigma of pregnancy was reported by $62 \%$ of 73 cardiovascular fellows at 1 institution in another survey, who also thought that their program was not flexible in accommodating the training schedule for new parents. ${ }^{14}$ Overall, the regulations for fellows' parental leave are not uniform among GME programs, and most of the programs do not provide sufficient paid leave for new parents. Therefore, there is a substantial need for a national policy to address the issue.

What would a proposal formulated by the ACGME and/or endorsed by the American Society of Neuroradiology look like? We would suggest that a paid leave duration of 8 weeks for primary caregivers and 4 weeks for secondary caregivers (no matter whether a traditional or nontraditional family situation) that is separate from sick and vacation leave would be in line with current practice. Parents would be eligible for additional unpaid leave of up to 12 weeks maximum. Because the FMLA may not be applicable to most of the fellows, we recommend that additional unpaid leave not be defined on the basis of on the FMLA. 
To take $>8$ weeks' leave from a 12 -month fellowship seems to conflict with ACGME and ABR expectations for that training period; therefore, a make-up period after the expected fellowship end date would be advisable, assuming that the fellow still is able to fulfill all the necessary skills laid out in fellowship training guidelines. In this survey, we found that larger programs are more likely to offer paid paternal leave also, with more frequent arrangements for paternal leave. Therefore, national proposals should consider the challenges that smaller programs would face when having $\geq 1$ fellow out on parental leave, for example by regulating flexible arrangements for elective rotations.

In the interest of the fetus, excluding the fellow from any radiation-exposure rotations for at least the first 2 trimesters would likely not incur too great a burden on the fellowship program and coworkers. Breastfeeding facilities should be provided within all radiology departments, and the time allotted should be determined according to the American College of Radiology Commission for Women and General Diversity and the American College of Radiology Commission on Human Resources. ${ }^{15}$ In this regard, Robbins et al ${ }^{16}$ showed that implementation of a policy to provide a private location and specific time for lactating residents in a residency department can easily contribute to balance between milk expression and patient care, decrease anxiety, and reduce time away from work for breastfeeding mothers.

We believe that the results of our survey are representative of American neuroradiology fellowships because the responses included 66 of 87 (76\%) neuroradiology fellowship programs listed through the ACGME site. Although the response rate to surveys of physicians varies widely in the literature, the American Medical Association has suggested in its landmark article entitled "Response Rates and Nonresponse Errors in Surveys" that those surveys covering $60 \%$ of the available pool are legitimate. ${ }^{17}$ The authors, Johnson and Wislar, ${ }^{17}$ equated a response rate of $60 \%$ to that of a $P$ value of .05 , and this has been adopted by the JAMA review process. Although many techniques have been explored as to how to increase physician participation in surveys, frequent reminders by e-mail have been shown to be most effective. ${ }^{18}$ Providing monetary incentives to increase physician engagement has not led to increased response rates. Internet and email-based reminders are more effective than postal mailbased surveys, but alternate modes of reminding such as mailing in a handwritten envelope might help increase response rates by as much as $11 \% .{ }^{18}$ Given that our response rate exceeds PLoS One and American Medical Association guidelines, we believe the results are valid.

Our study has several limitations, but they do not detract from the results provided. The survey response rate of $76 \%$ could have been improved but has been legitimized by previous citations referred to above. The questions were not vetted by a professional survey creator (ie, Gallup Poll or Reuters Ipsos). Phrasing some questions with "do you" rather than "would you" or "does your policy address" might have contributed to some of the negative answers. We had an "I do not know" response on several questions of up to $20 \%$, which also impacts the results. It is conceivable that the experience of PDs in their current position may have influenced their answers to some of the questions; this piece of data was not collected, and the responses were not adjusted by variable weighting. Some PDs referred to the FMLA provisions, even though 12-month fellows recruited from another facility are not eligible for them (see above). Some PDs follow institutional policies that may supersede any suggested policies by the ACGME, ABR or American Society of Neuroradiology.

\section{CONCLUSIONS}

Although most neuroradiology fellowship programs have maternal (94\%) and paternal (77\%) leave policies, the paid and unpaid duration of the leave varies widely. Current practices on making up call duties, dealing with radiation exposure, nontraditional family units, and breastfeeding provisions are also nonuniform. The neuroradiology PDs surveyed appeared open to a standardized policy proposal by organized radiology and would likely embrace its implementation.

\section{ACKNOWLEDGMENTS}

We sincerely thank all neuroradiology fellowship program directors who took time to respond the survey and provided valuable feedbacks.

Disclosures: David M. Yousem-UNRELATED: Consultancy: MRIOnline.com Comments: unpaid; Expert Testimony: medicolegal; Payment for Lectures Including Service on Speakers Bureaus: American College of Radiology Education Center, MRIOnline.com; Royalties: Elsevier for 5 books, informational analytics; Payment for Development of Educational Presentations: MRIOnline. com. Doris Lin-UNRELATED: Consultancy: ICON Medical Imaging, Bracco, Guerbet; Grants/Grants Pending: National Institutes of Health, Siemens.* *Money paid to the institution.

\section{REFERENCES}

1. S.1131 - A bill to establish family and medical leave banks to provide paid leave for employees of the Department of Defense, and for other purposes. 116th Congress (2019-2020). Defense policy bill with paid parental leave for feds goes to president Trump's desk. https:// www.govexec.com/pay-benefits/2019/12/defense-policy-bill-paidparental-leave-feds-goes-president-trumps-desk/161952. Accessed February 8, 2020

2. S.345 - Family and Medical Leave Act of 1989101st Congress (19891990) U.S. Department of Labor. Family and medical leave act. https://www.dol.gov/agencies/whd/fmla. Accessed February 8, 2020

3. Society for Human Resource Management. Workplace Flexibility in the 21st Century. https://blog.shrm.org/sites/default/files/reports/09-0464 Workplace_Flexibility_Survey_Report_inside_FINALonline.pdf. Accessed February 8, 2020

4. Bergquist DE. Who's bringing up baby: the need for a national uniform parental leave policy. Law \& Inequality 1987;5:227

5. Accreditation Council for Graduate Medical Education. Policies and Procedures, Effective May 12, 2020. http://www.acgme.org/Portals/ 0/PDFs/ab_ACGMEPoliciesProcedures.pdf. Accessed February 8, 2020

6. Vassallo P, Jeremiah J, Forman L, et al. Parental leave in graduate medical education: recommendations for reform. $\mathrm{Am} \mathrm{J} \mathrm{Med}$ 2019;132:385-89 CrossRef Medline

7. American Board of Radiology. Certification requirements. https:// www.theabr.org/diagnostic-radiology/initial-certification/certificationrequirements. Accessed February 8, 2020

8. Sherbaf FG, Lin DD, Yousem DM. Parental leave policy in radiology residency programs: current status. J Am Coll Radiology 2020 Apr 7. [Epub ahead of print] CrossRef Medline 
9. List of ACGME Accredited DR Residency Programs - acgme-i. https://apps.acgme.org/ads/Public/Programs/Search?stateId=\& specialtyId=91\&city. Accessed January 10, 2020

10. American Society of Neuroradiology. Fellowship programs. https:// www.asnr.org/education/fellowship-portal/fellowship-program-list. Accessed January 10, 2020

11. West DL, Nguyen H. Ethnic and gender diversity in radiology fellowships. J Racial Ethn Health Disparities 2017;4:432-45 CrossRef Medline

12. Weiss J, Teuscher D. What provisions do orthopaedic programs make for maternity, paternity, and adoption leave? Clin Orthop Relat Res 2016;474:1945-49 CrossRef Medline

13. Dixit A, Feldman-Winter L, Szucs KA. Parental leave policies and pediatric trainees in the United States. J Hum Lact 2015;31:434-39 CrossRef Medline
14. Mwakyanjala EJ, Cowart JB, Hayes SN, et al. Pregnancy and parenting during cardiology fellowship. J Am Heart Assoc 2019;8:e012137 CrossRef Medline

15. Arleo EK, Fielding JR, Lightfoote JB, et al. Radiology and radiation oncology practices should provide lactation facilities for all eligible employees. J Am Coll Radiology 2015;12:1127-28 CrossRef Medline

16. Robbins JB, Shubeck SP, Kanters AE, et al. Lactation policy and resources for trainees in the department of radiology. J Am Coll Radiology 2019;16:365-68 CrossRef Medline

17. Johnson TP, Wislar JS. Response rates and nonresponse errors in surveys. JAMA 2012;307:1805-06 CrossRef Medline

18. Brtnikova M, Crane LA, Allison MA, et al. A method for achieving high response rates in national surveys of US primary care physicians. PLoS One 2018;13:e0202755 CrossRef 